\title{
Coping strategies used by caregivers of children with newly diagnosed brain tumors
}

\author{
Alexandra Cutillo, MA, ${ }^{1}$ Kathrin Zimmerman, BA, ${ }^{2}$ Susan Davies, $\mathrm{PhD},{ }^{3}$ Avi Madan-Swain, $\mathrm{PhD},{ }^{4}$ \\ Wendy Landier, PhD, ${ }^{4}$ Anastasia Arynchyna, $\mathrm{MPH},{ }^{2}$ and Brandon G. Rocque, MD, MS ${ }^{2}$ \\ 1Department of Psychology, University of Alabama at Birmingham; 'Division of Pediatrics, Department of Neurosurgery, \\ University of Alabama at Birmingham; ${ }^{3}$ Department of Health Behavior, School of Public Health, University of Alabama at \\ Birmingham; and ${ }^{4}$ Division of Hematology/Oncology, Department of Pediatrics, University of Alabama at Birmingham, Alabama
}

\begin{abstract}
OBJECTIVE The goal of this study was to determine what strategies caregivers use to cope with the stress of a child who has recently undergone surgical treatment for a newly diagnosed brain tumor. Results will be used to improve psychosocial assessments and treatments provided to these families during initial hospitalization.

METHODS Caregivers of children with newly diagnosed brain tumors admitted to Children's of Alabama were enrolled during the child's initial hospitalization for surgical treatment from April 2016 to August 2017. The single-item, National Comprehensive Cancer Network visual analog Distress Thermometer (DT) was administered. Clinical and demographic variables were collected from the medical record. Approximately 1 month after patients were discharged from the hospital, caregivers participated in a semistructured interview that included questions about parent and family coping strategies. Broad questions about stress management since diagnosis were followed by specific questions about individual coping strategies. Interviews were recorded, transcribed, and coded for common themes. Themes were broadly characterized as adaptive versus maladaptive coping. Analysis was then performed to determine if DT scores or clinical or demographic factors were associated with the presence of maladaptive coping using a concurrent triangulation mixed-methods design.
\end{abstract}

RESULTS Caregivers identified several adaptive coping strategies, such as active coping, acceptance coping, emotionfocused coping, spiritual coping, social support, and posttraumatic growth. Maladaptive coping strategies were mostly categorized as avoidant coping. Caregivers endorsed multiple different coping strategies (mean of 4.59 strategies per caregiver). No clinical or demographic variables, whether the tumor was benign or malignant, or the DT score correlated with caregiver endorsement of maladaptive coping strategies.

CONCLUSIONS Caregivers of children newly diagnosed with brain tumors employ a number of coping strategies, some of which are maladaptive. The authors have not identified any method for predicting who is at risk for maladaptive coping. Assessment of coping skills and education about coping have the potential to improve overall care delivery to these families.

https://thejns.org/doi/abs/10.3171/2018.7.PEDS18296

KEYWORDS pediatric brain tumor; distress; coping; brain tumor treatment; oncology

$\mathrm{T}$ HE initial hospitalization for a pediatric brain tumor carries a host of potentially distressing factors for the patient and family. Although surgical treatment can be lifesaving, it can also result in neurological deficits that affect activities of daily living and cognitive function. Parents struggle to make important decisions in the best interest of their child. ${ }^{1,18}$ The stress of a pediatric brain tumor can have a long-lasting psychosocial impact and result in changing family dynamics over time..$^{20}$

Previous studies have indicated that parental stress is significant, with up to $51 \%$ of parents of a child with a brain tumor experiencing clinically significant levels of distress. ${ }^{1}$ Many parents also report a reduced quality of life during their child's brain tumor treatment. ${ }^{8}$ Prior studies have demonstrated that caregiver distress is related to child distress and adjustment, suggesting that active management of caregiver distress can positively impact the family unit. ${ }^{15}$ While many families cope or adjust well to a brain tumor diagnosis, there is a subset that experiences significant difficulties. In one study, over $35 \%$ of survivors 
and $29 \%$ of their parents reported severe posttraumatic stress symptoms. ${ }^{4}$ It is important for medical providers to understand family adjustment to a pediatric brain tumor in order to make appropriate recommendations and referrals.

Understanding the ways in which caregivers cope with a child's diagnosis of a brain tumor can help medical providers anticipate, assess for, and identify caregivers who may be having difficulty managing the emotional, physical, and practical demands of the diagnosis on the family. It is common for caregivers to perceive themselves as having difficulty coping, but understanding the specific ways in which these caregivers struggle to cope will assist in the development of interventions geared toward adaptive coping and adjustment with pediatric brain tumor diagnosis. ${ }^{18}$ Importantly, the way that a caregiver copes with an initial diagnosis or stressful event can predict a child's later adjustment, suggesting that early coping is important for future adjustment and should be addressed as soon as possible. ${ }^{11,15,21}$ This study aims to evaluate early caregiver coping in relation to a child's brain tumor.

There are several ways to conceptualize domains of coping strategies. They are sometimes considered to fall into broad dichotomous categories such as approach coping (i.e., strategies oriented toward confronting the stressor) versus avoidance coping (i.e., strategies used to distract from the stressor), problem-focused versus emotionfocused coping, or adaptive versus maladaptive coping. The definitions of these main domains as well as relevant subcategories tend to vary based on the relevant primary stressor. Coping style does influence mental health outcomes, with more negative, emotion-focused coping (i.e., self-blame/negative affect, avoidance, and substance use) being associated with depression and posttraumatic stress symptoms. ${ }^{9}$ Avoidant coping strategies in general are less adaptive and can lead to a greater presence of psychiatric symptoms. ${ }^{6,12,19}$ Conversely, active coping has been found to reduce anxiety, somatoform disorder, substance issues, and thought disorder. ${ }^{19}$

There is a dearth of qualitative evaluations of the coping mechanisms employed by caregivers of children with brain tumors, especially during the period soon after diagnosis. Per our literature review, there has been no qualitative assessment of coping strategies utilized by caregivers of children with a new diagnosis of a brain tumor (i.e., within 2 months of diagnosis). Quantitative investigations of coping with the diagnosis as well as qualitative investigations during treatment for brain cancer suggest that information seeking and social support are the most commonly utilized strategies. ${ }^{13,18,20,22}$ A qualitative investigation of caregiver coping at diagnosis will help providers to identify specific strategies that are helpful to caregivers, and to design methods to teach these useful strategies to caregivers who may be using more maladaptive coping strategies, such as avoidance.

The goal of this mixed-methods study is to use patientcentered qualitative techniques to determine what strategies caregivers use to cope with the stress of having a child diagnosed with and surgically treated for a brain tumor. Understanding the adaptive and maladaptive ways caregivers cope can help us design recommendations to families in the future.

\section{Methods \\ Participants}

Participants were recruited as part of a study to assess family and patient psychosocial needs following a new brain tumor diagnosis. The overall study included 40 participants. Data for this project are from a subset of these participants, the first 22 to complete interviews. Semistructured interviews were conducted, transcribed, and coded until thematic saturation was reached. Thematic saturation is the principle on which sample size in qualitative research is based, whereby the sample size is not based on numbers needed for a mathematical calculation, but rather for the collection of rich, detailed information., ${ }^{2,10}$ When analysis of 2 consecutive interviews no longer provided any new themes or ideas, we considered enrollment complete and thematic saturation reached.

Recruitment took place at a large pediatric hospital in the southeastern United States that diagnoses and treats 25 to 40 new brain tumor patients per year. All primary caregivers of patients admitted to the hospital with a new brain tumor diagnosis and undergoing surgical treatment were eligible for enrollment. Participants were recruited during their child's initial hospitalization for brain tumor surgery. Enrollment took place over an 18-month period from April 2016 to August 2017.

\section{Procedures}

Caregivers of children who received surgical treatment for a brain tumor were eligible for inclusion in the present study. Ethics approval was obtained from the hospital's institutional review board. Study consent was obtained by a research assistant during hospitalization. At the time of enrollment, caregivers rated their level of distress using the National Comprehensive Cancer Network Distress Thermometer (DT) ${ }^{14}$ The DT is an 11-point visual analog scale that measures the level of distress from 0 to 10 . It has been validated for use in both pediatric and adult brain tumor patients and in families of pediatric patients. ${ }^{7,17}$

Semistructured interviews were conducted approximately 1 month after hospital discharge and took place during a routine follow-up visit in the neurosurgery clinic, in the oncology clinic, or via telephone. Qualitative methods were used to obtain an in-depth understanding of coping mechanisms utilized by caregivers during the 1 st month after a child's surgery.

Interviews were conducted by a psychology doctoral student (A.C.) trained in research ethics, administration of appropriate informed consent, and qualitative data collection methods. The interviewer used an interview guide that included open-ended questions designed to obtain information about coping, stress management, and individual coping strategies. Caregivers were first asked broadly about stress management over the previous month and then specifically about individual coping strategies. Interviews were audio recorded, transcribed, and coded for common themes. See Table 1 for a sample interview question and suggested probes to demonstrate how interviews were conducted.

Clinical and demographic data, including age, sex, parental marital status, preoperative neurological status, and 
tumor histology, were collected by review of the electronic medical record.

\section{Data Analysis}

A concurrent triangulation mixed-methods design was used to conduct this study. ${ }^{5}$ In studies with this design, qualitative and quantitative data are collected concurrently. The data are analyzed separately and then compared. This method has allowed us to evaluate themes identified during the qualitative component of the research and then analyze these themes with respect to clinical variables and the DT. Coding criteria were developed based on a phenomenological approach, an attempt to fully describe a phenomenon or "lived experience," to allow for a detailed thematic classification of coping experiences. Transcriptions of interviews were reviewed, and parent descriptions of coping mechanisms used during the initial diagnosis period were coded for common themes and coping domains. Common codes were organized into coping domains based on previous literature. ${ }^{4}$ Coding criteria were determined by 3 of the authors, a psychology doctoral student with experience working with families in medical settings (A.C.), a neurosurgeon with experience treating brain tumor patients (B.G.R.), and a health behavior researcher with expertise in qualitative methods (S.D.). These 3 individuals each independently coded interviews and resolved any coding discrepancies until reaching agreement on how to create/categorize codes. Codes were then clearly defined on a final code sheet. The final code structure was composed of distinct codes, each with subcodes for detailed thematic classification. After all the interviews had been coded by the psychology doctoral student, they were reviewed. Validation checks were performed by having a team member individually code a random $33 \%$ of the interviews.

Using clinical and demographic data, chi-square tests of association and t-tests were used to determine whether those caregivers who utilized maladaptive coping mechanisms (avoidance, self-blame, anger, and rumination) differed significantly from those who did not endorse any maladaptive coping mechanisms. Finally, to assess the representativeness of the sample of caregivers who were interviewed versus the total study population, clinical and demographic variables were compared in these 2 groups using chi-square and t-tests.

\section{Results}

Demographic characteristics of the patients who completed semistructured interviews were similar to those who did not complete semistructured interviews (Table 2). There was no statistically significant difference in demographic characteristics or preoperative neurological status between those who did and did not participate in interviews. There was also no significant difference in level of distress in the 2 groups. However, caregivers who participated in semistructured interviews were more likely to have children who were diagnosed with malignant tumors $(\mathrm{p}=0.03)$.

We identified the following themes of caregiver coping that emerged from semistructured interviews. They can be broadly characterized into 2 main categories: adaptive

\section{TABLE 1. Excerpt from interview guide}

\begin{tabular}{ll}
\hline Question & $\begin{array}{c}\text { People respond to stress in many different ways. How } \\
\text { did you cope with the news of your child's tumor? }\end{array}$ \\
\hline Probes & Did you reach out to family members and friends? \\
& Did you need help with chores or other responsibilities? \\
& Did you search for information [online]? \\
& Did you ask the doctors a lot of questions? \\
& Did you keep to yourself? \\
& Did you feel overwhelmed? \\
& Did you turn to your faith? \\
& Did you access support online? \\
\hline
\end{tabular}

coping, defined as healthy and adaptive ways of reducing stress that are beneficial to the user and can be maintained over time; and maladaptive coping, defined as mechanisms that are nonconstructive, are not effective over time, and ultimately increase stress. Types of adaptive coping included 1) active coping, 2) acceptance coping, 3) emotion-focused coping, 4) social support coping, 5) spiritual coping, and 6) posttraumatic growth. Maladaptive coping was most often avoidance coping. Definitions of each main domain of coping and subcategories of coping mechanisms are included in Table 3, based on definitions used by Carver et al. in developing the COPE inventory. ${ }^{4}$ Categorization into adaptive and maladaptive coping was based on review of the literature. , $^{4,21}$ Active coping, such as information seeking, was the most common coping strategy, endorsed by $95 \%$ of participants. Nearly all participants also endorsed using acceptance coping and emotion-focused coping; 64\% described using some type of avoidance coping. All participants described using more than one coping strategy (mean number of coping strategies 4.59 , range $2-7$ ). Table 4 provides caregiver quotations to illustrate the coping strategies, and Table 5 provides a quantitative summary of how many participants utilized each coping strategy.

\section{Adaptive Coping Mechanisms}

Active Coping

Active coping mechanisms utilized by caregivers included information seeking (i.e., internet research, asking questions, utilizing a hospital white board to track treatment goals and questions for the medical team, seeking out educational materials, taking notes, blogging; e.g., "The more knowledge you have, the more you can meet with that person and be able to talk and discuss"), maintaining normalcy (e.g., "Let them continue to do things that they enjoy....That's their normal"), self-care/boundary setting (e.g., "Sometimes I just need a little space"), celebrating small victories (e.g., "It's a long road....and the distance ahead looks so much longer if you don't...celebrate those little [victories] here and there"), and planning (i.e., taking one step at a time, staying in control, and facing problems head on; e.g., "We're at letter A. And we're not gonna talk about B, C, D, E, F, or Z until we get past A").

\section{Acceptance Coping}

Caregivers who utilized acceptance coping were able to 
TABLE 2. Sample characteristics

\begin{tabular}{|c|c|c|c|c|}
\hline Variable & Total Sample $(n=40)$ & Interview Subset $(n=22)$ & No Interview $(n=18)$ & Interview vs No Interview $p$ Value \\
\hline Parent's sex & & & & 0.48 \\
\hline Male & $7(18)$ & $3(14)$ & $4(22)$ & \\
\hline Female & $33(82)$ & $19(86)$ & $14(78)$ & \\
\hline Marital status & & & & 0.11 \\
\hline Single & $9(22)$ & $7(32)$ & $2(11)$ & \\
\hline Married & $26(65)$ & $14(64)$ & $12(67)$ & \\
\hline Divorced & $5(12)$ & $1(5)$ & $4(22)$ & \\
\hline Parent education & & & & 0.59 \\
\hline Less than high school & $5(12)$ & $2(9)$ & $3(17)$ & \\
\hline High school & $6(15)$ & $4(18)$ & $2(11)$ & \\
\hline Started college & $8(20)$ & $6(27)$ & $2(11)$ & \\
\hline Finished college & $13(32)$ & $6(27)$ & $7(39)$ & \\
\hline Started graduate school & $1(2)$ & $0(0)$ & $1(6)$ & \\
\hline Completed graduate school & $7(18)$ & $4(18)$ & $3(17)$ & \\
\hline Child's sex & & & & 0.25 \\
\hline Male & $25(62)$ & $12(55)$ & $13(72)$ & \\
\hline Female & $15(38)$ & $10(45)$ & $5(28)$ & \\
\hline Tumor histology & & & & 0.03 \\
\hline Benign & $15(38)$ & $5(23)$ & $10(56)$ & \\
\hline Malignant & $25(62)$ & $17(77)$ & $8(44)$ & \\
\hline Neurological status & & & & 0.61 \\
\hline No deficits or seizures & $20(50)$ & $10(45)$ & $10(56)$ & \\
\hline Mild deficits & $9(22)$ & $5(23)$ & $4(22)$ & \\
\hline Moderate deficits & $9(2)$ & $5(23)$ & $4(22)$ & \\
\hline Severe deficits & $2(5)$ & $2(9)$ & $0(0)$ & \\
\hline Mean age of children, yrs & $7.55(5.83)$ & $8.09(5.94)$ & $6.89(5.80)$ & 0.26 \\
\hline DT score & $7.20(2.57)$ & $6.77(2.78)$ & $7.72(2.27)$ & 0.25 \\
\hline
\end{tabular}

Values are presented as the number of patients (\%) unless stated otherwise. Mean values are presented as the mean (SD).

TABLE 3. Definitions of coping styles

\begin{tabular}{|c|c|}
\hline Coping Style & Definition \\
\hline Adaptive coping strategies & Effective ways of reducing stress that are beneficial to the user and can be maintained over time. \\
\hline Active coping & $\begin{array}{l}\text { Increasing awareness of the stressor, changing the way that one thinks about the stressor, and taking steps } \\
\text { toward reducing stress by utilizing one's own resources. }\end{array}$ \\
\hline Acceptance coping & Willingness to acknowledge the stressor and tolerate a difficult situation. \\
\hline Emotion-focused coping & Managing the emotions associated with the stressor. \\
\hline Coping through social support & $\begin{array}{l}\text { Emotional support, informational support, and instrumental support. Emotional support refers to the offering of } \\
\text { empathy and compassion. Informational support refers to offering help through the provision of information. } \\
\text { Instrumental support includes providing assistance to others through direct actions. }\end{array}$ \\
\hline Spiritual coping & Relying on religious beliefs, practices, and community to manage a stressor. \\
\hline Posttraumatic growth & Positive change as a result of adversity or a traumatic life event. \\
\hline Maladaptive coping strategies & Mechanisms that are nonconstructive, are not effective over time, and ultimately increase stress. \\
\hline Avoidance coping & $\begin{array}{l}\text { Thinking and acting in ways that will prevent an individual from having to confront a stressor. Emotional avoidant } \\
\text { coping includes neglecting to confront or acknowledge the feelings surrounding a stressor or the stressor } \\
\text { itself, and active avoidance is defined as taking steps to hide the reality of a stressor from one's self or others. }\end{array}$ \\
\hline $\begin{array}{l}\text { Other types of maladaptive } \\
\text { coping }\end{array}$ & $\begin{array}{l}\text { Rumination (repeatedly focusing attention on a stressor without the ability to problem-solve or think of other } \\
\text { things), self-blame, and anger. }\end{array}$ \\
\hline
\end{tabular}


TABLE 4. Quotations of participants illustrating coping domains

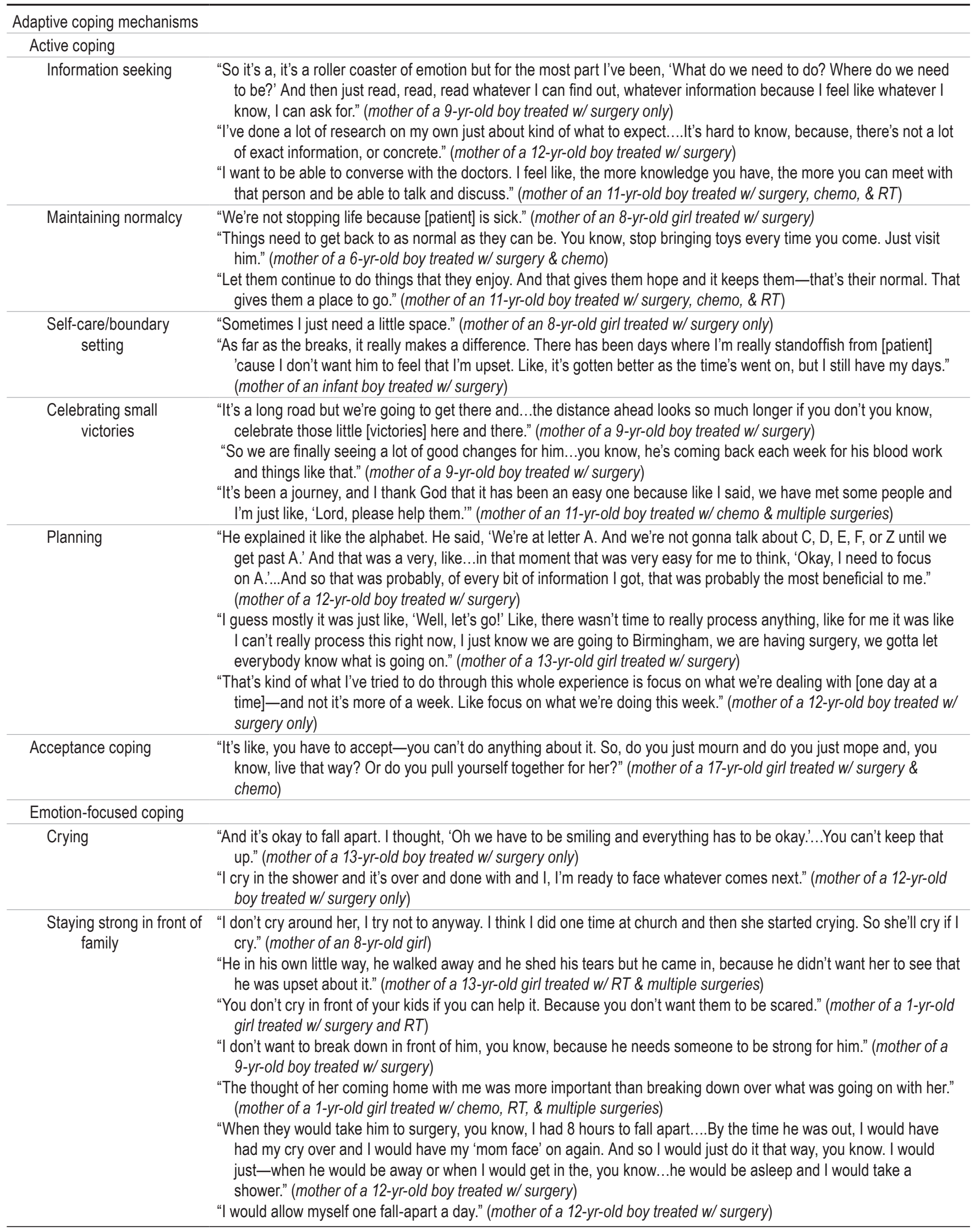




\section{» CONTINUED FROM PAGE 34}

\section{TABLE 4. Quotations of participants illustrating coping domains}

\begin{tabular}{|c|c|}
\hline \multicolumn{2}{|l|}{$\begin{array}{l}\text { Adaptive coping mechanisms } \\
\text { (continued) }\end{array}$} \\
\hline $\begin{array}{l}\text { Emotion-focused coping } \\
\text { (continued) }\end{array}$ & \\
\hline $\begin{array}{l}\text { Strength of patient } \\
\text { supports family }\end{array}$ & $\begin{array}{l}\text { "She is also my, my coping mechanism." (mother of a 13-yr-old girl treated w/ RT \& multiple surgeries) } \\
\text { "[Patient] said, 'Well, I kind of understand a little bit, but um, God's going to take care of me and the doctors are going } \\
\text { to do what they...know how to do, and me worrying is not going to make it any better and change it.' And we just } \\
\text { started crying because we didn't, we were like, we're still learning those things, like, as adults we're still learning." } \\
\text { (mother of a 9-yr-old boy treated w/ surgery) } \\
\text { "I had to get it together because he was like, 'Mama, they have to get it out, then let's do it." (mother of an 11-yr-old } \\
\text { boy treated w/ chemo \& multiple surgeries) } \\
\text { "We did really good because [patient] was so strong." (mother of 17-yr-old girl treated w/ surgery \& chemo) }\end{array}$ \\
\hline $\begin{array}{l}\text { Talking about } \\
\text { feelings }\end{array}$ & $\begin{array}{l}\text { "I'm like, 'Okay. We're gonna have one time a day where we just let everything out that we're feeling. And we have a } \\
\text { big cry, let it out, and then we'll be good.'... Like, there were days that he would say 'Mom, I just need to cry.' And so } \\
\text { we would sit there and we would cry and we would talk about what we were feeling and then he would be like, and } \\
\text { we would do that for as long as he needed, which would usually be } 10 \text { or } 15 \text { minutes, and then he'd be like, 'Alright, } \\
\text { l'm okay now." (mother of a 12-yr-old boy treated w/ surgery only) } \\
\text { "We've let him know that if he needs to talk about something...you know, and we talk to him...usually at bed time, } \\
\text { 'cause that's usually more relaxed, you know, non-, I guess, confrontational type conversation that you can have. } \\
\text { Just hanging out." (mother of an 8-yr-old boy treated w/ multiple surgeries) }\end{array}$ \\
\hline
\end{tabular}

Social support

Emotional support "We live in a small town and our-my work family_our community came together. Our ball family, I mean, our community came together and came and prayed with us." (mother of an 11-yr-old boy treated w/ surgery, chemo, \& RT)

"We had people we've never met before come up here and support us and pray for us and we had thousands of people praying for him...through social media, through other people's church." (mother of an infant boy treated w/ surgery, chemo, \& RT)

"You get such an informal support network anyways with the parents you see out in the waiting room." (mother of a 17-yr-old girl treated $w /$ chemo \& multiple surgeries)

Informational support "Everybody gave me information. So if there was a question that I didn't think to ask of, I knew I could call them or email and, you know. So I felt very supported." (mother of a 12-yr-old boy treated w/ surgery)

"We have some friends who are going through the same thing at the same time as us. So...we kind of bounce some things off." (mother of an 8-yr-old boy treated w/ multiple surgeries)

Instrumental support "Grandparents are there, my sister, aunts, uncles, everyone has pitched in to help out with, um, I mean even friends, their friends, like [sibling]'s volleyball team...everyone has been great down there and helped out." (mother of a 9-yr-old boy treated w/ surgery)

Spiritual support

Faith-based coping

"I tell people just keep believing in God, keep praying, keep reading the Bible, and God will do what He got to do. If it's not their time, He's not gonna take them. But if it is, we can't blame Him." (mother of a 1-yr-old girl treated w/ RT \& multiple surgeries)

"We givin' it to God and letting Him handle this with us." (mother of a 13-yr-old girl treated w/ RT \& multiple surgeries)

"God really showed me who He was. So I was like, 'Why me?' in the beginning....And then, when you look at the beauty of everything and how he made it out of every surgery." (mother of an infant boy treated w/ RT, chemo, \& multiple surgeries)

"The doctor can tell you anything, but the Lord, He can turn it all around. You just, you mean, you know you just got to be strong, you got to have faith. Yep, you got to believe." (mother of a 7-yr-old boy treated w/ surgery)

Prayed as a last resort "Everybody prays when they feel like they don't have any other options....When I thought things were the worst, I prayed to everybody that, everybody and everything that I could think of." (mother of a 2-yr-old boy treated w/ chemo \& multiple surgeries)

Positive growth/posttrau- "You appreciate life more, better than, you know. You never think that something like that could happen to you." matic growth (mother of an infant boy treated w/ surgery, chemo, \& RT)

"Now I understand. It's to help me be stronger, to help me be better. As a person, as a mother, as a church member, as a friend. It helped me mature." (mother of an infant boy treated w/ surgery, chemo, \& RT) 


\section{» CONTINUED FROM PAGE 35}

\section{TABLE 4. Quotations of participants illustrating coping domains}

\begin{tabular}{|c|c|}
\hline \multicolumn{2}{|c|}{ Maladaptive coping strategies } \\
\hline Avoidant coping & \\
\hline Active avoidance & 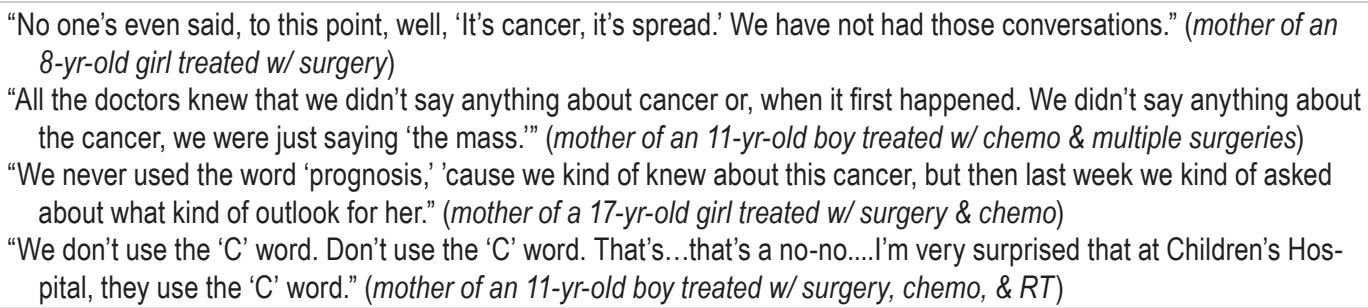 \\
\hline Emotional avoidance & $\begin{array}{l}\text { "I was like, okay. If this is the type of tumor they say she havin', that means only have this amount of time. That was } \\
\text { just unacceptable." "A lot of people try to bring her old videos, pictures....She doesn't want to look at it." (mother of } \\
\text { an 8-yr-old girl treated w/ surgery) } \\
\text { "He kind of had an episode, you know, kind of got a little freaked out about it. And we kind of joked with him and tried } \\
\text { to turn it around...we kind of made a joke about it to kind of get it." (mother of an 11-yr-old boy treated w/ surgery, } \\
\text { chemo, \&RT) }\end{array}$ \\
\hline \multicolumn{2}{|l|}{ Other maladaptive coping } \\
\hline Rumination & $\begin{array}{l}\text { "I stay up literally, some nights, sometimes I won't sleep for } 2 \text { days just sitting up thinking what happened." (mother of } \\
\text { a 1-yr-old girl treated w/ chemo, RT, \& multiple surgeries) }\end{array}$ \\
\hline Self-blame & $\begin{array}{l}\text { "I was saying, 'Why my baby? What happened? What did I do wrong as a parent? Where did this come from?'" } \\
\text { (mother of an } 11 \text {-yr-old boy treated w/ chemo \& multiple surgeries) }\end{array}$ \\
\hline Anger & $\begin{array}{l}\text { "I get mad. I get ill. It just eats at me to where I don't want to. I just get away from everybody." (mother of an 11-yr-old } \\
\text { boy treated w/ surgery, chemo, \& RT) }\end{array}$ \\
\hline
\end{tabular}

Chemo = chemotherapy; RT = radiation therapy.

understand the reality of their child's diagnosis and treatment and that it cannot be changed and were able to search for ways to move forward despite these challenges. "So do you just mourn and do you just mope and, you know, live that way? Or do you pull yourself together for her?"

\section{Emotion-Focused Coping}

Caregivers utilized crying (e.g., "I cry in the shower and it's over and done with and I'm ready to face whatever comes next"), staying strong in front of family (e.g., "You don't cry in front of your kids if you can help it. Because you don't want them to be scared"), finding support in the patient's strength (e.g., "I had to get it together because he was like, 'Mama, they have to get it out, then let's do it."'), and talking about emotions associated with the situation (e.g., "Okay, we're gonna have one time a day where we just let everything out that we're feeling").

\section{Coping Through Social Support}

Most caregivers (91\%) used social support as a coping mechanism by relying on their family, friends, medical teams, and communities. These communities included work, church, children's sports teams, other caregivers in the hospital, and online through social media and blogs (e.g., "We live in a small town and our...community came together. Our ball family, I mean, our community came together...and prayed with us").

\section{Spiritual Coping}

A significant number of caregivers endorsed utilizing faith-based coping through praying, trusting in God's plan, and attending or streaming religious services. One caregiver did not identify as particularly religious or spiritual, but did utilize praying when she felt that she did not have any other options to cope (e.g., "Everybody prays when they feel like they don't have any other options....When I thought that things were the worst").

\section{Posttraumatic Growth}

A small group of caregivers $(n=5)$ discussed posttraumatic growth, including an appreciation for life, becoming a stronger person, and maturing through this experience (e.g., "You appreciate life more....You never think that something like that could happen to you").

\section{Maladaptive Coping}

Avoidance Coping

Caregivers avoided the child's diagnosis and treatment by hiding the diagnosis from the child (e.g., "We have not had those conversations"), not using the word "cancer" (e.g., "We don't use the 'C' word"), avoiding organizations and materials related to the child's diagnosis, and terminating activities that prompt thoughts of the diagnosis or activities that have become difficult because of the diagnosis (e.g., "A lot of people try to bring her old videos, pictures....She doesn't want to look at it").

\section{Other}

Other maladaptive coping strategies included selfblame (e.g., "What did I do wrong as a parent?"), anger, 
TABLE 5. Coping mechanisms used by caregivers of children with brain tumors

\begin{tabular}{|c|c|c|}
\hline Coping Domain & No. of Caregivers & $\%$ \\
\hline \multicolumn{3}{|l|}{ Adaptive coping mechanisms } \\
\hline Active coping & 21 & 95 \\
\hline Information seeking & 20 & 91 \\
\hline Planning & 7 & 32 \\
\hline Celebrating small victories & 17 & 77 \\
\hline Relaxation/mindfulness & 2 & 9 \\
\hline Self-care/boundary setting & 5 & 23 \\
\hline Distraction/staying busy & 5 & 23 \\
\hline Maintaining normalcy & 5 & 23 \\
\hline Acceptance coping & 1 & 5 \\
\hline Emotion-focused coping & 20 & 91 \\
\hline Social support & 20 & 91 \\
\hline Emotional support & 20 & 91 \\
\hline Informational support & 4 & 18 \\
\hline Instrumental support & 5 & 23 \\
\hline Spiritual coping & 17 & 77 \\
\hline Posttraumatic growth & 5 & 23 \\
\hline \multicolumn{3}{|l|}{ Maladaptive coping mechanisms } \\
\hline Avoidance coping & 14 & 64 \\
\hline Emotional avoidance & 9 & 41 \\
\hline Active avoidance & 13 & 59 \\
\hline Other maladaptive coping & 3 & 14 \\
\hline Rumination & 1 & 5 \\
\hline Self-blame & 1 & 5 \\
\hline Anger & 1 & 5 \\
\hline
\end{tabular}

A mean of 4.59 (SD 1.56; range 2-7) strategies per caregiver were used.

and rumination (e.g., "I stay up literally, some nights, sometimes I won't sleep for 2 days just sitting up thinking what happened").

When comparing families who endorsed any maladaptive coping strategies with those who did not, we found no significantly significant difference in demographic characteristics (Table 6). There was no difference in the use of maladaptive coping strategies among caregivers based on their child's tumor histology (i.e., benign or malignant) or preoperative neurological status. Finally, there was no significant difference in level of distress among participants who did and did not endorse the use of avoidant coping.

\section{Discussion}

This mixed-methods study examined the coping strategies that caregivers of children diagnosed with and surgically treated for a brain tumor utilized within the first 2 months after diagnosis. Our results indicate that these caregivers use a variety of multiple coping strategies. In particular, most caregivers utilized active, emotionfocused, and spiritual coping as adaptive coping mechanisms. Avoidance coping was the most commonly used maladaptive coping strategy.

The most commonly endorsed coping strategy was ac-
TABLE 6. Differences among participants who used or did not use maladaptive coping strategies

\begin{tabular}{|c|c|c|c|}
\hline & $\begin{array}{c}\text { Maladaptive } \\
\text { Coping } \\
(n=15)\end{array}$ & $\begin{array}{c}\text { No } \\
\text { Maladaptive } \\
\text { Coping } \\
(n=7)\end{array}$ & $\begin{array}{c}\mathrm{p} \\
\text { Value }\end{array}$ \\
\hline \multicolumn{4}{|l|}{ Variable } \\
\hline Parent's sex & & & 0.16 \\
\hline Male & $1(7)$ & $2(29)$ & \\
\hline Female & $14(93)$ & $5(71)$ & \\
\hline Marital status & & & 0.63 \\
\hline Single & $4(27)$ & $3(43)$ & \\
\hline Married & $10(67)$ & $4(57)$ & \\
\hline Divorced & $1(7)$ & $0(0)$ & \\
\hline Parent education & & & 0.36 \\
\hline Less than high school & $2(13)$ & $0(0)$ & \\
\hline High school & $4(27)$ & $0(0)$ & \\
\hline Started college & $3(20)$ & $3(43)$ & \\
\hline Finished college & $4(27)$ & $2(29)$ & \\
\hline Started graduate school & $0(0)$ & $0(0)$ & \\
\hline Completed graduate school & $2(13)$ & $2(29)$ & \\
\hline Child's sex & & & 0.45 \\
\hline Male & $9(60)$ & $3(43)$ & \\
\hline Female & $6(40)$ & $4(57)$ & \\
\hline Tumor histology & & & 0.66 \\
\hline Benign & 12 & 5 & \\
\hline Malignant & 3 & 2 & \\
\hline Neurological status ${ }^{*}$ & & & 0.37 \\
\hline No deficits or seizures & $7(47)$ & $3(43)$ & \\
\hline Mild deficits & $2(13)$ & $3(43)$ & \\
\hline Moderate deficits & $4(27)$ & $1(14)$ & \\
\hline Severe deficits & $2(13)$ & $0(0)$ & \\
\hline \multicolumn{4}{|l|}{ Patient present during interview* } \\
\hline Yes & 5 & 3 & 0.67 \\
\hline No & 10 & 4 & \\
\hline Mean age of children, yrs & $8.33(5.55)$ & $7.57(7.16)$ & 0.79 \\
\hline Mean DT score & $7.27(2.19)$ & $5.71(3.73)$ & 0.34 \\
\hline
\end{tabular}

Values are presented as the number of participants (\%) unless stated otherwise. Mean values are presented as the mean (SD).

${ }^{*}$ Post hoc analysis.

tive coping, with the most commonly reported mechanism being information seeking. This finding confirms other research that has suggested a need for systematic provision of specific information for caregivers. In a quantitative, longitudinal study of parental coping in the context of a child's diagnosis with an embryonal tumor, results indicated that, at the time of diagnosis, parents were most likely to utilize approach coping responses (directly addressing the stressor and attempting to make change through action), with the most common methods being seeking support, guidance, and information. ${ }^{16}$

In the present study, the second most commonly reported coping mechanism was emotion-focused coping, 
which included crying, staying strong in front of family, using the strength of the patient as a source of support, and talking about feelings related to the child's diagnosis and treatment. This finding corroborates previous findings that mothers caring for a child with a brain tumor drew strength from their love for their children and the responsibility of being a mother. ${ }^{18}$ In this study, maintaining a positive attitude was viewed as a responsibility of being a mother.

Similar to prior findings, social support was an important factor in coping in our sample. Specifically, most participants (91\%) sought emotional support from their friends and families. A smaller group of caregivers sought informational or instrumental/practical support from others. Importantly, many caregivers indicated that relationships with other caregivers in the hospital with children with similar medical conditions contributed to their ability to cope. The importance of social support in bolstering adaptive coping by promoting self-esteem and confidence has been previously reported. ${ }^{13}$ Furthermore, individuals with supportive friends and families tend to engage in more active coping strategies. ${ }^{11}$ These results support the systematic assessment of a family's social support network, as this may be an important resource to promote adaptive coping with the diagnosis.

We found no association between the presence of maladaptive coping strategies and demographic characteristics, tumor histology, or level of distress in this sample. Previous studies have shown that maladaptive coping can be related to negative psychological diagnoses and mood disturbance. ${ }^{15,21}$ Therefore, it is important to assess coping skills in those at risk for maladaptive coping. Our findings show no variables significantly associated with maladaptive coping. We would thus argue that risk stratification is not possible, and that all families should be assessed for and educated about coping strategies. If families are utilizing maladaptive coping strategies like avoidance, it may be beneficial for them to be referred to a mental health provider to help support the development and use of more adaptive coping strategies for the promotion of more positive adjustment.

This study has the following limitations. First, most interviews were conducted during clinic visits, but 2 were conducted via telephone. Phone interviews did not allow the interviewer to observe or display nonverbal communication, which could have potentially made these interviews less personal or comprehensive. In-person interviews were conducted in neurosurgery or oncology clinic rooms, which may have drawn up memories and emotions that were not necessarily accessed by caregivers during phone interviews. Second, the patient was present and/or participated in some of the semistructured interviews with caregivers $(n=8,36 \%)$. A caregiver with a child in the room might not have been as candid about the challenges they have faced as a caregiver alone, especially considering the many caregivers interviewed who shared that they make efforts to stay strong and not show difficult emotions in front of their child. However, patients present in the room were either younger than 2 years $(n=3)$ or were teenagers who wanted to contribute to the conversation and share insights about their experiences. Post hoc analy- sis showed no difference in reporting maladaptive coping strategies among caregivers whose children were or were not present during interviews (Table 6). Third, interviews addressed only parent coping and did not cover topics related to child coping mechanisms. While parent coping can influence child coping, it is important to uniquely assess for child coping, as a parent may not be completely aware of a child's primary coping mechanisms. Lastly, most of the caregivers interviewed (77\%) had a child who was diagnosed with a malignant brain tumor. Treatment of a child's brain cancer presents new challenges and prolonged physical, practical, emotional, and financial stress on a family. Coping resources may be utilized differently in the 1st month of treatment than they are during the 1st month after surgery alone. However, there was no difference in the report of maladaptive coping strategies among caregivers of children with benign or malignant tumor histology.

It will be helpful for providers to more deeply understand the experience of caregivers whose children have recently undergone brain tumor resection and the strategies used to cope with the stress of the first 2 months postsurgery. Understanding how caregivers cope is the first step in identifying those using maladaptive strategies. Information regarding what groups utilized adaptive coping mechanisms and what specific strategies were most useful can be used as a framework to assist caregivers endorsing maladaptive coping to develop adaptive coping strategies.

\section{Conclusions}

Results from the present study support the need to screen all families for distress and coping resources, regardless of treatment or demographic characteristics. Future analyses are needed to determine the relationship between initial caregiver coping strategies and adjustment, and child age, medical information, and/or demographic characteristics of caregivers.

\section{Acknowledgments}

This work was supported by NIH grant no. 1KL2TR001419.

\section{References}

1. Barraza M: The right thing. Narrat Inq Bioeth 4:39-42, 2014

2. Bennett E, English MW, Rennoldson M, Starza-Smith A: Predicting parenting stress in caregivers of children with brain tumours. Psychooncology 22:629-636, 2013

3. Bowen GA: Naturalistic inquiry and the saturation concept: a research note. Qual Res 8: 137-152, 2008

4. Carver CS, Scheier MF, Weintraub JK: Assessing coping strategies: a theoretically based approach. J Pers Soc Psychol 56:267-283, 1989

5. Compas BE, Jaser SS, Dunn MJ, Rodriguez EM: Coping with chronic illness in childhood and adolescence. Annu Rev Clin Psychol 8:455-480, 2012

6. Creswell JW, Clark V, Gutmann M, Hanson W: Advanced mixed methods research designs, in Tashakkori A, Teddlie C (eds): Handbook of Mixed Methods in Social \& Behavioral Research. Thousand Oaks, CA: Sage, 2003, pp 209-240

7. Deisinger JA, Cassisi JE, Whitaker SL: Relationships between coping style and PAI profiles in a community sample. J Clin Psychol 52:303-310, 1996 
8. Goebel S, Mehdorn HM: Measurement of psychological distress in patients with intracranial tumours: the NCCN distress thermometer. J Neurooncol 104:357-364, 2011

9. Goldbeck L: The impact of newly diagnosed chronic paediatric conditions on parental quality of life. Qual Life Res 15:1121-1131, 2006

10. Greening L, Stoppelbein L: Brief report: pediatric cancer, parental coping style, and risk for depressive, posttraumatic stress, and anxiety symptoms. J Pediatr Psychol 32:12721277, 2007

11. Guest G, Bunce A, Johnson L: How many interviews are enough? An experiment with data saturation and variability. Field Methods 18: 2016

12. Holahan CJ, Moos RH: Personal and contextual determinants of coping strategies. J Pers Soc Psychol 52:946-955, 1987

13. Jackson AC, Enderby K, O'Toole M, Thomas SA, Ashley $\mathrm{D}$, Rosenfeld JV, et al: The role of social support in families coping with childhood brain tumor. J Psychosoc Oncol 27:1-24, 2009

14. Litman JA: The COPE inventory: dimensionality and relationships with approach- and avoidance-motives and positive and negative traits. Pers Individ Dif 41:273-284, 2006

15. Moos RH, Holahan CJ: Dispositional and contextual perspectives on coping: toward an integrative framework. J Clin Psychol 59:1387-1403, 2003

16. National Comprehensive Cancer Network: Distress management. Clinical practice guidelines. J Natl Compr Canc Netw 1:344-374, 2003

17. Okado Y, Long AM, Phipps S: Association between parent and child distress and the moderating effects of life events in families with and without a history of pediatric cancer. $\mathbf{J}$ Pediatr Psychol 39:1049-1060, 2014

18. Palmer SL, Lesh S, Wallace D, Bonner MJ, Swain M, Chapieski L, et al: How parents cope with their child's diagnosis and treatment of an embryonal tumor: results of a prospective and longitudinal study. J Neurooncol 105:253-259, 2011

19. Patel SK, Fernandez N, Wong AL, Mullins W, Turk A, Dekel $\mathrm{N}$, et al: Changes in self-reported distress in end-of-life pediatric cancer patients and their parents using the pediatric distress thermometer. Psychooncology 23:592-596, 2014

20. Shortman RI, Beringer A, Penn A, Malson H, Lowis SP, Sharples PM: The experience of mothers caring for a child with a brain tumour. Child Care Health Dev 39:743-749, 2013
21. Vollrath M, Alnaes R, Torgersen S: Differential effects of coping in mental disorders: a prospective study in psychiatric outpatients. J Clin Psychol 52:125-135, 1996

22. Woodgate RL, Tailor K, Yanofsky R, Vanan MI: Childhood brain cancer and its psychosocial impact on survivors and their parents: A qualitative thematic synthesis. Eur J Oncol Nurs 20:140-149, 2016

\section{Disclosures}

The authors report no conflict of interest concerning the materials or methods used in this study or the findings specified in this paper.

\section{Author Contributions}

Conception and design: Rocque, Davies, Madan-Swain, Landier. Acquisition of data: Rocque, Cutillo, Arynchyna. Analysis and interpretation of data: all authors. Drafting the article: all authors. Critically revising the article: Rocque, Cutillo, Zimmerman, Davies, Madan-Swain, Landier. Reviewed submitted version of manuscript: all authors. Approved the final version of the manuscript on behalf of all authors: Rocque. Statistical analysis: Rocque, Cutillo, Davies, Arynchyna. Administrative/technical/ material support: Rocque, Arynchyna. Study supervision: Rocque, Davies, Madan-Swain, Landier.

\section{Supplemental Information}

\section{Previous Presentations}

Portions of this work were presented in poster form at the Association for Clinical and Translational Science Annual Meeting, Washington, DC, April 18-21, 2017.

\section{Correspondence}

Brandon G. Rocque: University of Alabama at Birmingham, AL. brandon.rocque@childrensal.org. 